\title{
Gestão por Padronização de Processos: A percepção dos Enfermeiros de Centro Cirúrgico
}

\author{
Standardized Process-Based Management: The perception of Surgical Center Nurses \\ Gestión por Estandarización de Procesos: Una percepción de los Enfermeros del Centro \\ Quirúrgico
}

Anderson Costa Richa ${ }^{1}$, Solange Machado Guimarães ${ }^{2}$, Teresinha Valdugo Cardoso ${ }^{3}$

\begin{abstract}
RESUMO: Objetivo: revelar a visão de Gestores Enfermeiros de Centro Cirúrgico sobre o modelo de gestão por padronização de processos. Método: pesquisa exploratória, descritiva, com abordagem qualitativa, realizada no segundo semestre de 2011. A população-alvo deste estudo foram 19 alunos do Curso de Pós-Graduação de Enfermagem em Centro Cirúrgico da Universidade Luterana do Brasil (ULBRA), dos quais sete participaram por meio de entrevistas com perguntas abertas, analisadas pelo método de Bardin. Resultados: após a análise emergiram seis categorias: o entendimento sobre processo de trabalho; a relevância da padronização de processos; os resultados obtidos com a padronização; a adesão e o envolvimento da equipe; as ferramentas aplicadas, e o monitoramento através de indicadores. Conclusão: todos os entrevistados reconhecem que padronizar promove o desenvolvimento orientado de seu trabalho, refletindo diretamente nos resultados. Este estudo abre espaço para maiores discussões no que diz respeito ao pouco tempo dedicado às atividades gerenciais em detrimento da necessidade da atuação assistencial.
\end{abstract}

PALAVRAS-CHAVE: Centro Cirúrgico. Padronização de processos. Gestão.

ABSTRACT: Objective: to reveal the vision of Surgical Center nurse-administrators on the management model by standardization processes. Method: an exploratory, descriptive study with qualitative approach carried out in the second half of 2011. Nineteen nurses from the Surgical Nursing Graduate program at Universidade Luterana do Brasil - ULBRA were the target population of this study; nine of them participated through interviews conducted with open questions analyzed by the Bardin method. Results: the following six categories emerged after analysis: understanding the work process, the importance of process standardization, results obtained with standardization, membership and staff involvement; applied tools; and monitoring by indicators. Conclusion: all respondents recognize that standardization motivates the whole team to develop their work, reflecting directly in the results. This study paves the way for further discussion regarding the short time devoted to management activities over the need for assistance.

KEYWORDS: Surgical Center. Standardization Process. Management.

RESUMEN: Objetivo: conocer la visión de los Enfermeros Directores del Centro Quirúrgico acerca del modelo de gestión por estandarización de procesos. Método: investigación exploratoria, descriptiva, con enfoque cualitativo, realizada en el segundo semestre de 2011. La población objeto de estudio fue de 19 alumnos del Curso de Postgrado de Enfermería en el Centro Quirúrgico de la Universidade Luterana do Brasil (ULBRA), siete de los cuales participaron a través de entrevistas con preguntas abiertas, que posteriormente fueron analizadas por el método de Bardin. Resultados: tras el análisis, surgieron seis categorías: entendimiento del proceso de trabajo; importancia de la estandarización de procesos; resultados obtenidos con la estandarización; adhesión y participación del equipo; herramientas aplicadas; y seguimiento a través de indicadores. Conclusión: todos los entrevistados reconocen que la estandarización promueve el desarrollo orientado de su trabajo, reflejándose directamente en los resultados. Este estudio abre el camino para mayores discusiones sobre cómo el poco tiempo dedicado a las actividades de gestión puede causar un detrimento en la necesaria tarea asistencial.

PALABRAS CLAVE: Centro Quirúrgico. Estandarización de procesos. Gestión.

${ }^{1}$ Acadêmico de Enfermagem do $8^{\circ}$ Semestre, Universidade Luterana do Brasil.

Rua Doutor Alfredo Ângelo Filho, 972. Bairro Igara. Canoas, RS, Brasil.

Telefone: (51) 8451-6982. E-mail: anderson.richa@yahoo.com.br

${ }^{2}$ Orientadora: Enfermeira e Docente, Curso de Graduação em Enfermagem. Universidade Luterana do Brasil. E-mail: solange.machadoguimaraes@ gmail.com

${ }^{3}$ Co-orientadora: Enfermeira e Docente, Curso de Graduação. Universidade Luterana do Brasil. E-mail: terevalduga@gmail.com 


\section{Introdução}

É na instituição de saúde que o paciente/cliente deposita a maior parcela das expectativas do bom desempenho profissional, além da garantia de segurança. Por esse motivo, os processos e as pessoas que envolvem o paciente cirúrgico devem receber atenção especial ${ }^{1}$.

A Unidade de Centro Cirúrgico é o conjunto de elementos destinados às atividades cirúrgicas, bem como à recuperação pós-anestésica e pós-operatória imediata² ${ }^{2}$ É um setor singular dentro do hospital por tratar de situações complexas e pela evidência dos resultados apresentados, além de decisivo na ação curativa ${ }^{3}$.

As organizações são constituídas por uma complexa combinação de recursos humanos e organizacionais ${ }^{4}$. A estrutura de uma organização é definida como a soma dos modos pelos quais o trabalho pode ser dividido; define-se, também, como a coordenação das atividades realizadas por cada indivíduo 5 .

O Enfermeiro tem função preponderante na articulação dos processos. Não é raro que ele seja o ponto de convergência deste sistema. A ele, cabe a organização e a distribuição das informações pertinentes aos demais envolvidos, tornando-se o elo entre os diferentes profissionais da área da saúde e da área administrativa, sendo, posteriormente, o elo entre estes e o cliente ${ }^{6}$.

Atribui-se, também, cada vez mais, a este profissional, o envolvimento nas decisões financeiras e nos planejamentos orçamentários do setor ou da instituição, tendo que gerir recursos (materiais, humanos e financeiros) muitas vezes escassos. É dele a missão, como agente de mudanças, de alcançar o equilíbrio entre qualidade, quantidade e custos em seu local de atuação ${ }^{3}$.

Um dos grandes desafios enfrentados pelas instituições de saúde é como manter um bom padrão de qualidade no atendimento e, ainda assim, controlar e reduzir custos. A resposta a esta pergunta passa pela padronização de processos ${ }^{7}$.

O funcionamento de uma organização está baseado num conjunto de atividades transformadoras e inter-relacionadas. Assim, para agregar valor ao negócio, é fundamental mapear e padronizar as atividades em processos, e conhecer as necessidades e expectativas das partes interessadas ${ }^{2,4}$.

Podem-se definir processos como um conjunto de atividades interativas que transformam insumos (entradas) em produtos (saída) $)^{1-4}$.

A satisfação das partes interessadas é alcançada pela tradução de suas necessidades e expectativas em requisitos para os produtos/serviços, e seu desdobramento para cada processo na cadeia de valor ${ }^{4}$.

De acordo com a definição do Escritório de Avaliação Tecnológica dos Estados Unidos da América do Norte, qualidade de um prestador é o grau em que o processo de assistência aumenta a probabilidade de resultados desejados pelos pacientes e reduz a probabilidade de resultados não desejados ${ }^{1}$.

Dessa forma, considerando a importância do Centro Cirúrgico no contexto da manutenção financeira do hospital, a alta complexidade que representa as atividades ali realizadas e, ainda, a experiência profissional - que proporciona uma contínua análise crítica sobre gestão por padronização de processos -, surgiu o interesse em abordar este tema, do qual se pretendeu possível extrair significativos resultados para uma melhor análise.

Julga-se, ainda, que o assunto se faz relevante para a comunidade científica e, em especial, para o profissional Enfermeiro que, em muitas ocasiões, é o principal administrador das Unidades de Centro Cirúrgico nos hospitais. Ressalte-se, também, a importância desta pesquisa para as instituições hospitalares e os seus usuários, que buscam continuamente a qualidade nos serviços prestados, como oferta e preferência, respectivamente.

O objetivo geral deste trabalho foi considerar e analisar a visão dos gestores de Centro Cirúrgico sobre a gestão por padronização de processos deste setor. Paralelamente, mediante os objetivos específicos, propõe-se avaliar os benefícios da padronização de processos em Unidades de Centro Cirúrgico e identificar as principais dificuldades encontradas pelos envolvidos na implantação da padronização de processos.

\section{Método}

Esta pesquisa constitui um estudo exploratório, descritivo, de abordagem qualitativa. A população-alvo foram 19 Enfermeiros matriculados no curso de Pós-Graduação em Centro Cirúrgico da Universidade Luterana do Brasil (ULBRA), dois quais sete enfermeiros foram incluídos na amostra de acordo com os critérios de inclusão e exclusão desta pesquisa.

Os critérios de inclusão foram: a) estar cursando PósGraduação em Centro Cirúrgico; b) estar atuando em quaisquer áreas do Centro Cirúrgico, e c) aceitar participar da pesquisa.

Os critérios de exclusão foram: a) não estar presente nos dias de entrevista; b) não estar desenvolvendo atividades profissionais em Centro Cirúrgico, e c) não aceitar participar da pesquisa.

O instrumento de coleta foi uma entrevista semiestruturada, conduzida por um formulário de perguntas abertas, que exploraram o tema relacionado. As perguntas norteadoras do estudo foram:

- Qual é a visão dos gestores do Centro Cirúrgico sobre os indicadores de padronização de processos?

- Quais são as vantagens e os benefícios deste controle de qualidade para o profissional Enfermeiro?

A coleta de dados ocorreu no mês de setembro de 2011, tão logo o projeto foi aprovado pelo Comitê de Ética da ULBRA/ Canoas, pela Coordenadora do Curso de Enfermagem 
da ULBRA/Canoas, com realização do estudo-piloto. Inicialmente, houve a apresentação do autor da pesquisa aos alunos do Curso de Especialização de Pós-Graduação de Enfermagem com ênfase em Centro Cirúrgico, ocasião em que foram expostos os objetivos deste estudo e realizado o convite para participação do mesmo. Os interessados receberam o Termo de Consentimento Livre Esclarecido $(\mathrm{TCLE})^{8}$. Após leitura e preenchimento deste material, foram realizadas entrevistas individuais, com gravação na íntegra.

Os dados coletados foram transcritos e analisados qualitativamente, por meio da técnica de Análise de Conteúdo de Bardin, pela categorização temática, seguindo os seguintes passos: a) pré-análise; b) exploração do material; c) tratamento dos resultados e interpretação ${ }^{9}$. Iniciou-se a primeira fase, mediante minuciosa transcrição das entrevistas realizadas.

Os entrevistados foram codificados neste estudo através da letra $\mathbf{S}$, seguida de numeração ordinária crescente correspondente a cada entrevistado. Efetivada a leitura deste material, os discursos dos entrevistados foram cruzados, conectando pontos em comum, delimitando, assim, as categorias.

Em seguida, foram relacionadas as respostas com a fundamentação bibliográfica consultada. Cada categoria gerou uma discussão e análise.

\section{Resultados e discussão}

A interpretação deste material gerou resultados coerentes com o objetivo deste estudo e ainda revelou novos temas a serem abordados pela comunidade científica. Ao mesmo tempo, pode ser considerado material fidedigno para consultas e apoio a outros estudos.

Deste estudo, surgiram resultados e discussões em seis categorias estabelecidas pelo método de Bardin, quais sejam: i) o entendimento sobre processo de trabalho; ii) a relevância da padronização de processos; iii) os resultados obtidos com a padronização; iv) a adesão e o envolvimento da equipe; v) as ferramentas aplicadas, e vi) o monitoramento mediante indicadores.

\section{Categoria I - Entendimento sobre processos de trabalho}

A teoria do sistema foi a primeira, das abordagens administrativas, a considerar que a organização se compõe de partes que se integram entre si e são interdependentes. A dinâmica dos sistemas consiste na entrada de elementos que são transformados, pela sequência de processos, e geram saídas que levam aos resultados ${ }^{5}$. Assim, podem-se definir processos como sendo uma série de tarefas ou etapas que recebem insumos, tais como materiais, informações, pessoas, métodos e máquinas, que geram produto físico ou serviço ${ }^{10}$.

Por esta categoria, ficou evidenciado, pelas respostas dos entrevistados, que processo se define como atividades realizadas para transformação de uma matéria-prima em um produto final:

[...] eu entendo como os meios que a gente leva para chegar ao objetivo [...] para chegar no resultado.(S2)

É aquilo que vocêfaz para transformar uma coisa numa outra coisa. (S5)

[...] é o caminho que a gente utiliza, a forma que a gente encontra para chegar num objetivo, para chegar num resultado. (S6)

Os entrevistados buscaram, em suas experiências diárias, meios para elucidar a resposta. Aparece, então, a importância de conceituar, descrever, registrar, de padronizar tudo o que é feito:

[...] processos, então, é na verdade a descrição de todas as atividades que a gente realiza né, em qualquer setor. (S1) [...] éapadronizaçãodetudo que agentefaz. Éescrever, determinar, o que fazer, como fazer e quem faz as coisas do dia a dia. (S4) [...] é aquilo que se faz dentro da instituição hospitalar e que normalmente a gente registra. É tudo aquilo que se faz, como se faz, dentro da instituição hospitalar. (S7)

As respostas, de certa forma, legitimaram a ligação positiva e direta que se faz entre processos de trabalho e padronização.

\section{Categoria II - Relevância da padronização de processos}

A padronização é uma importante ferramenta gerencial e, como tal, nos ambientes administrativo e técnico, confere uniformidade às ações, além de reduzir a dispersão e possibilitar que cada profissional realize seus serviços de forma orientada e segura; a padronização começa pela compreensão de todo o processo ${ }^{8,11}$.

O pensamento sistêmico é o entendimento das relações de interdependência entre os diversos componentes de uma organização, bem como a organização e o ambiente externo $0^{4}$.

A padronização estimula a criatividade e a participação de toda a equipe, trazendo, em sua essência, o conceito de melhoria contínua. O padrão eficaz é aquele que está permanentemente melhorando, através da experiência dos que o utilizam².

Está muito evidente, nas respostas dos entrevistados, que a percepção de padronização de processos seja algo que viabiliza, de maneira positiva, o trabalho:

[...] as pessoas, sabendo o que devem fazer, vão fazer melhor. A qualidade vai aparecer [...](S5)

Está se falando de, através deste modelo, criar um ambiente motivador e organizado, em que se busca não apenas a conclusão de uma tarefa e sim o prazer de estar realizando a mesma; por consequência, se está ofertando qualidade ao nosso produto final:

[...] no momento que tu padroniza, tu descreve o processo, tu vai orientar toda a sua equipe a fazer da mesma forma, para ter uma melhor qualidade na assistência e no teu serviço. (S1) 
Levando-se em questão o fato de vários profissionais estarem trabalhando visando atingir um objetivo em comum, padronizar significa orientar cada pessoa que participa do processo a desenvolver seu trabalho em prol da continuidade. Isso, de certa forma, enfatiza a importância de cada um dentro do sistema, além de propiciar o seu entendimento como um todo:

[...] tendo isso padronizado, todomundo vaifazerdessaforma.(S1)

[...] todo mundofala a mesma língua, age da mesma maneira.(S6)

[...] é fazer com que profissionais diferentes façam o mesmo procedimento, da mesma forma. É como foi pré-determinado. (S7)

As ferramentas que compõem este modelo aparecem como peças importantes, segundo os entrevistados. Eles justificam que é necessário buscar fundamentação para o tema proposto, a fim de credibilizá-los perante toda a equipe, mostrar seus benefícios e sua eficácia:

[...] padrão está em cima de pesquisa, avaliação, das características de cada lugar e tem que adequar. (S6) [...] é determinar como será feito, independente daquele que está aplicando, que está fazendo, fazer da mesma forma. É padronizar. (S7)

Talvez seja este um dos segredos para o desafio de todos aqueles que trabalham o comprometimento junto aos recursos humanos:

[...] que a meta é ter a questão de estar todo mundo trabalhando pro mesmo lado. Tu faz um caminho a percorrer neste trabalho, na forma que tu entende que é a melhor e todo mundo seguir ela. Então, se todos seguirem aquilo que tá documentado ali, que foi uma coisa que foi estudada para ser feita, que é a melhor forma, porque sempre que tu vai padronizar um processo tu vai pesquisar uma coisa, tu vai te fundamentar pra que esse processo que tu padronizou tenha alguma eficácia né, tenha um benefício com isso. (S2)

\section{Categoria III - Resultados obtidos com a padronização}

Hoje, um complicador no planejamento fiscal das organizações de saúde envolve o alcance de duas metas: a contenção de custos e a qualidade do cuidado, as quais nem sempre possuem um relacionamento linear ${ }^{12}$. Este desafio vem exigindo da equipe de saúde e dos administradores um progressivo entrosamento ${ }^{7}$.

A qualidade é o julgamento feito com base na satisfação do cliente com o produto ou o serviço utilizado. Com isso, o objetivo de uma empresa deve ser o reconhecimento das necessidades do cliente e sua satisfação em relação aos serviços e produtos ${ }^{13}$.

Escolher um modelo de gestão que garanta sucesso é uma aposta diária frente à flexibilidade do desafio mercadológico. As padronizações de processos vêm apresentando bons resultados. Conforme trechos das entrevistas a seguir, padronizar gera otimização:

[...] se prioriza coisas, se vai direto ao que tem que ser feito [...] (S4)
Seus ganhos refletem, principalmente, nos termos redução de custos e melhoria na qualidade dos serviços prestados:

[...] é bem interligado sim, custo e controle da qualidade do serviço, porque, com a padronização do processo, a gente otimiza as rotinas e também a gente otimiza os nossos colaboradores. Ele pode estar realizando mais atividades se ele tem a atividade dele padronizada [...] (S1)

Assim, conforme citado nas categorias anteriores, o modelo estudado permite que as pessoas realizem suas atividades de maneira orientada, em que cada passo do processo tenha sido avaliado previamente, calculando os seus benefícios. Deste modo, delineando redução de custos, os entrevistados citaram que a padronização controla custos de cada serviço prestado, gera eliminação de desperdício de materiais, otimiza o tempo, diminui o número de suspensão de cirurgias, entre outros benefícios:

[...] tu padroniza um processo, que tu elimina um desperdício, que todo mundo gasta aquela quantidade de material necessário, que todo mundo registra aquele procedimento que é necessário registrar daquela forma, tu vai montar a receita, aumentar, tendo a mesma quantidade de trabalho né, e diminuir os custos através do desperdício e da forma errada de trabalhar que tu vai minimizar. Tu vai economizar tempo e dinheiro na verdade. (S2) [...] a gente padronizou um número xis de materiais e se viu que com aquilo ali, tu fazia o procedimento correto e adequado, com a técnica correta e tu diminuía o custo de algumas coisas que não tinha necessidade de ter como tu tinha antes. (S3) [...] se a gente padronizar que o necessário são dois, resumindo isso tudo, olha a economia que agente vai ter. Então isso vale para tudo, vale para um atendimento de uma situação, para uso de medicação, então a padronização sim, ela gera economia, ela repercute. (S5)

Assim, referenciando o aumento de qualidade dos serviços prestados, os entrevistados relacionaram padronização com a otimização dos colaboradores, que apresentam maior segurança na realização de suas atividades, maior agilidade e, consequentemente, gerando menor tempo de espera por parte do cliente, e uniformização do atendimento, aumentando a confiabilidade e a fidelização junto à instituição:

[...] melhora a qualidade em todos os sentidos. O processo de trabalho acaba tendo melhor qualidade e quem acaba ganhando com isto é o próprio paciente. (S6)

[...] todo mundo trabalhando da mesma forma, pensando da mesma maneira, cuidando do seu paciente com o mesmo fim determinado, que é prestar assistência de qualidade. (S4)

[...] se cada um fizer igual ele vai ver, mas tem qualidade, tem uma padronização e todo mundo sabe o que está fazendo. É uma questão de confiabilidade do trabalho. (S5)

Por fim, o ganho que se tem está em todas as instâncias: instituição, colaborador e cliente:

[...] tu diminui erros e a agilidade é o principal. Quem ganha com isso? O paciente e a instituição, mas, em primeiro, lugar o paciente. (S3)

[...] a partir do momento que todos começam a fazer da mesma forma, aí vem o ganho em longo prazo. Quem ganha com isso? A instituição, até mesmo porque envolve a qualidade do atendimento, mas também o controle de custos. Tudo isso é muito importante para o profissional, para a instituição e isso aí reflete para o paciente. (S7) 


\section{Categoria IV - A adesão e o envolvimento da equipe}

A padronização começa pela compreensão do processo como um todo ${ }^{11}$. A implantação dos protocolos exige envolvimento multidisciplinar, profissionais competentes, grandes investimentos em pesquisas e um bom sistema de informações ${ }^{1}$.

Este entendimento sobre o conceito da padronização dos processos estimula a criatividade e a participação de toda a equipe, trazendo em sua essência o conceito de melhoria contínua. O padrão eficaz é aquele que está permanentemente melhorando, advindo da experiência dos que o utilizam ${ }^{4}$.

A adesão a este método é uma tarefa difícil, pois é necessário muito mais do que redigir passos. Ela é um modelo norteador daqueles que trabalham o processo:

[...] é uma forma deles se embasar, uma forma de consulta deles, entendeu. O meu funcionário ainda prefere essa forma documentada. (S2)

Para tal tarefa, comprometer as pessoas tem sido uma barreira para conquista dos objetivos. A diversidade de formação, de cultura e de ideias vem, muitas vezes, dispersando atenções. Além disso, padronizar gera trabalho, esforço e comprometimento contínuo. Nas entrevistas, os Enfermeiros relatam que muitas vezes isto gera resistência. Existe, por parte dos colaboradores, certa comodidade:

[...] eu trabalho lá dois anos e pouco e para eu me adaptar a isso eu confesso que foi um pouco difícil. (S4) [...] eles não gostam, eles têm bastante resistência. É uma briga contínua para fazer com que eles leiam, pra fazer [...] (S5) [...] então, às vezes, não se tem aquele movimento de que se precisa ter para que as coisas aconteçam. (S7) [...] então, se eu falo em padronizar processos e fazer capacitação, aumenta o seu trabalho. Então, isso aí, infelizmente na maioria das vezes, não é bem visto, porque já se faz de uma forma e daquele jeito já está bom. (S7) [...] a cooperação deixa a desejar [...] falta o comprometimento. (S7)

Por outro lado, os Enfermeiros reclamam da falta de orientação. Sabem que os resultados de padronizar o processo facilitam o fluxo de trabalho, trazendo bons resultados:

[...] é uma própria exigência deles pra que essa informação seja difundida entre todos. (S2) [...] uma coisa nova, a primeira reação às vezes não é muito boa. Então tu vai colocando que com isso se vai ganhar, que todo mundo ganha e eles entendem que é para o bem e ajudam a fazer. (S3) [...] às vezes, tem alguma resistência, mas eles acabam aderindo e acabam fazendo. Pelo conhecimento dos benefícios? Isso aí, pelo conhecimento das vantagem que aquilo vai trazer né. (S3)

Por meio de caminhos bem descritos, documentos claros e informações precisas, todos terão embasamento na sua tarefa, apoio científico e respaldo em resposta a uma cobrança. É nesse caminho que os gerentes trabalham comprometimento. Trazendo os colaboradores para a formação do processo. Tornando-os parte:
[...] eles opinam e decidem junto como vai ser, pra gente chegar num consenso e daí todo mundo vai fazer aquilo e daí realmente o pessoal faz. Cooperam e se comprometem. E eu sinto até que eles preferem, porque daí eles sabem o que seguir. (S1) [...] se eu preciso de alguma coisa para o meu paciente e eu preciso do médico, então eu sei que eu vou ter que ligar para o médico e ele sabe que vai ter que me dar o retorno né. Isso é bem específico assim. (S4)

Junto a isso, a constante avaliação e a cobrança realizada pelos gestores também são citadas como pontos chave na padronização:

[...] se eu tenho uma padronização, eu vou cobrar do meu funcionário porque tem alguém que me cobra também. E eles já estão inseridos no sistema e eles aceitam bem. Eles aceitam muito bem lá. (S4) [...] eu acho que é por isso que funciona. Tem alguém que cobra. Todo mundo tem que entrar no mesmo ritmo. Até por que é assim, desde o primeiro dia que tu entra lá tu já é cobrado [...] (S4)

\section{Categoria V - Ferramentas aplicadas}

O Centro Cirúrgico, por suas particularidades, constitui uma das unidades mais complexas do ambiente hospitalar. $\mathrm{Na}$ sua rotina, ocorrem vários processos e subprocessos, direta e indiretamente ligados à produção de cirurgias. Assim, percebe-se que o bom desempenho de um Centro Cirúrgico está diretamente relacionado com a qualidade de seus próprios processos e com os processos dos serviços que o apoiam ${ }^{14}$.

A representação gráfica e sistematizada do processo é a forma mais usual para compreendê-lo. A esta representação denomina-se fluxograma do processo. O fluxograma permite que as etapas soltas sejam ordenadas de uma forma sistemática, com níveis variáveis de detalhamento, e definindo com clareza quem é cliente, quem é fornecedor, a sequência em que as coisas acontecem, os possíveis passos duplicados, ciclos de retrabalho, a posição em que cada um se insere e o seu grau de participação. Os fluxogramas facilitam a visualização das etapas críticas, dos problemas em potencial e das etapas passíveis de padronização ${ }^{7}$.

O Procedimento Operacional Padrão (POP) é o documento final e mais elementar da padronização. Este descreve cada passo crítico que deverá ser dado pelo seu operador para garantir o resultado esperado da tarefa ${ }^{7,14}$.

O processo de padronização exige, logicamente, ferramentas que sejam fontes de consultas das pessoas que trabalham com processos. É, por estas, que o modelo se torna perceptível. Em suas entrevistas, os gestores citaram como ferramentas de padronização mais utilizadas, as reuniões com atas e os POPs:

[...] a gente faz uma convocação de uma reunião onde é passado e todos têm ciência da maneira de como deve proceder [...] (S3) [...] a ideia é disponibilizar estes POPs e não guardar na gaveta da Enfermeira. Que fique ali no balcão ao alcance do 
técnico e de outros profissionais para que tenha o acesso para que se utilizem. (S7)

[...] eu utilizo os POPs. A gente tem todas as atividades descritas, não temos todas ainda, mas já tem alguma coisa. E depois, isso é disseminado para a equipe. Eu determino em reuniões mensais, fica acesso fácil a todo mundo e também em loco, quando eu vejo que alguém não está fazendo como é descrito, na hora eu já converso, enfim, oriento. (S1)

Os entrevistados justificam que, por meio das reuniões, torna-se mais prático e dinâmico difundir novas decisões, normas ou regras estabelecidas:

[...] são feitas reuniões mensais, mas não com foco em padronização, e sim com o foco setorial em que a gente dá aquela pincelada no assunto específico. (S5) [...] para fortalecer tudo o que a gente faz, é através de reuniões, treinamentos, tudo o que a gente recebe a gente passa, o que tem, a gente relembra o pessoal, reforça, atualiza [...] (S6)

Quanto aos POPs, é uma ferramenta muito conhecida e utilizada na maioria dos hospitais, e que tem a função de descrições de atividades práticas, principalmente da Enfermagem.

Entretanto, os entrevistados confessam que são pouco utilizados, mesmo estando em fácil acesso:

[...] os POPs eu tenho numa pasta, na SR, ali dentro do Bloco, que os funcionários têm como consultar né. Normalmente eles não consultam muito, mas a gente fala pra eles, diz que está escrito ali e eles seguem. Mas tá documentado. Tá à disposição. (S2) [...] assim, no bloco, a gente utiliza os POPs. Ali onde eu estou, nunca vi ninguém pegar a pasta, nunca vi ninguém pegar nada. Ás vezes, usam o computador e tal [...] (S6)

Outra ferramenta utilizada na padronização de processos são os fluxogramas. Estes são menos referenciados, porém, apresentam resultados mais efetivos, visto que definem passos do processo de uma forma esquematizada, além de sua apresentação em murais os tornar mais atrativos:

[...] eu fiz o fluxograma desde que a gente tem o pedido do médico no agendamento, passa pela reserva do material, tudo desenhadinho $[\ldots](S 2)$

[...] Existem os fluxogramas colocados em sala de uma forma a resumir algumas situações mais importantes [...] (S5)

Por último, com o advento da Tecnologia da Informação (TI), os e-mails têm se apresentado como uma nova e boa opção de apresentação e divulgação dos padrões adotados:

[...] a gente recebe e-mails dizendo que determinada rotina mudou, ou, por exemplo, a chefe passa para gente e a gente passa adiante. (S4)

[...] o fluxograma eu tenho no mural do Bloco e divulguei ele por e-mail para todas as unidades, todos os setores do hospital que estão envolvidos no processo [...] (S2)

[...] tem os POPs, que são aquelas coisas mais específicas, assim, tipo o cateterismo, tipo assim, como preparar determinada coisa. E isso está disponível na Intranet. Cada computador pode ter acesso, então está ali para todos [...] (S4)
Por fim, tão importante quanto definir os objetivos, é fazer com que o caminho a percorrer seja difundido de maneira clara e atrativa, para que os colaboradores busquem as ferramentas, tornando-as parte de suas tarefas como fonte norteadora. É importante que todos os colaboradores participem da construção destas ferramentas, de maneira que se busque elaborar um documento fidedigno e condizente com a função, promovendo a continuidade do processo:

[...] a gente trabalha, o pessoal do dia trabalha com as ações diferenciadas, como a gente chama. São Enfermeiros que trabalham para cumprir carga horária porque não trabalham no final de semana. Então, agora eles acabaram de construir um manual da sala de recuperação. Então, naquele manual consta tudo o que o técnico tem que fazer, todas as rotinas da unidade, porque a empresa trabalha muito com rotina $e$ POP [...] (S4)

\section{Categoria VI - Monitoramento mediante indicadores}

O indicador é idealizado pelo serviço que o utilizará, proporcionando informações que podem variar de controles básicos assistenciais a indicadores administrativos ${ }^{13}$.

Condição importante para a construção de indicadores é a obtenção de dados e informações fidedignas, resultantes da anotação sistemática das ocorrências e dos eventos relativos ao funcionamento do Centro Cirúrgico ${ }^{14}$.

A análise do processo deve pautar-se na busca da melhoria contínua, ter caráter periódico e sistemático, e ter seus resultados sempre divulgados às partes interessadas ${ }^{14}$.

Todo processo gera resultados, sejam na forma de números, produtos ou serviços. Estes precisam ser continuamente avaliados. O uso de indicadores nas unidades de trabalho é um sistema seguro, que aponta a qualidade do produto final deste processo, assinalando também possíveis desvios, falhas ou, ainda, ajustes que podem ser dados ao sistema. O que se percebe pelos relatos dos entrevistados é que o trabalho com indicadores não faz parte das suas rotinas diárias:

[... ] na SR a gente não usa, não tem nada de indicador [...] (S4)

[...] não utilizei, mas tenho vontade [...] (S2)

Existe um desconhecimento das ferramentas ideais ou dos dados específicos a serem levantados nas Unidades de Centro Cirúrgico:

[...] não tenho [...] ainda me falta conhecimento para usar indicadores. Me faltam subsídios. Quais indicadores, onde aplicar, como aplicar, isso ainda me falta. (S1) [...] no momento, nós não estamos levantando indicadores dentro do Bloco. Eu nem sei quais indicadores usar [...] vamos buscar trabalhar com indicadores específicos do Bloco Cirúrgico [...]. (S7)

Nota-se que os processos são refletidos na medida em que falhas vão surgindo. As intervenções são paliativas em cima de dados isolados:

[...] empiricamente, ah deu problema aqui, tá com problema em tal processo. Não há um registro que eu vou passar ou vou evitar o resultado, essas intervenções que a gente fez. (S2) 
Ainda pelos relatos, extraiu-se que informações, números, fontes, são trabalhados, em sua maioria, no nível estratégico, o que constitui um erro. Tanto o nível tático quanto o nível operacional devem estar a par destes dados, trabalhando seus resultados e colocando em prática novos cursos, quando se fizer necessário. As áreas de apoio, como Setor de Controle de Infecção e Setor de Faturamento, foram citadas como áreas de consultas utilizadas para levantamento de dados:

[...] a gente lá tem, por exemplo, vários registros que servem como indicadores, os custos que são repassados pelo faturamento, com o que foi o gasto de material [...] (S6) Então, assim, a taxa de prescrição de Enfermagem a gente tem, eu acho que uma das coisas importantes que a gente tem ali na sala de recuperação [...] mas assim, não é a gente que faz. Não é nenhuma de nós que faz. É uma coisa que já vem pra gente. Então, tem uma pessoa certa que vê. (S4)

Ainda assim, revela-se a vontade de se ter o domínio dos dados relevantes que os indicadores trazem, a fim de poder direcionar melhor o gerenciamento do Centro Cirúrgico e, com isso, buscar resultados mais satisfatórios:

Mas eu queria poder usar ferramentas que eu conheço que me passam né, pra controlar melhor isso aí. (S2) [...] vamos buscar trabalhar com indicadores específicos do Bloco Cirúrgico. (S7)

Fica claro este anseio dos Enfermeiros em buscar elementos que ajuízem e creditem seu trabalho:

[...] quando a gente precisa, como se diz, provar alguma coisa, consultar alguma coisa a gente busca nos registros, pra procurar indicador, pra encontrar [...] (S3)

\section{Considerações finais}

Com o passar dos tempos, a arte de gerenciar processos ganhou novas investiduras, ampliando sua complexidade. Desenvolveram-se teorias, adotaram-se filosofias, apareceram inúmeras exigências, estabelecendo que administradores criassem modelos adaptativos ao mercado. Estabeleceuse, ainda, que o envolvimento na busca dos objetivos se descentralizasse da cúpula, para ser um compromisso de todos os colaboradores da instituição.

A grande oferta e a consequente concorrência fizeram com que surgisse, neste cenário, o item qualidade, como sendo um fator diferencial de mercado. Novas tecnologias foram agregadas em prol das necessidades do consumidor, fazendo com que os processos se tornassem mais dispendiosos. Surge, então, um dos principais desafios dos tempos modernos: a busca de equilíbrio entre ofertar serviços/produtos de qualidade aos menores custos possíveis.

Gerenciar serviços de saúde carrega um nível de complexidade muito grande. No Centro Cirúrgico, este desafio ganha maiores proporções. As metas deste setor estão envolvidas em uma grande carga emocional. A expectativa dos clientes reflete diretamente na atuação da equipe de saúde. O compromisso para que os resultados sejam maximizados torna o ambiente de trabalho tenso. Ali não são permitidos erros. Ainda, é neste setor, que os hospitais apostam em ter maior retorno financeiro, por tratar com tecnologias caras que se ofertam como qualidade de atendimento.

Em meio a todo este cenário, a Enfermagem, que tem como característica ser um serviço fim, vem agregando cada vez mais, à atuação assistencial, o compromisso gerencial. Assim, na padronização de processos, torna-se o elo mais forte na relação entre os setores e as equipes, e destes com os clientes.

Neste estudo, ficou evidenciado, pelos entrevistados, que padronizar processos gera um desencadeamento de bons resultados, capaz de atender às necessidades referendadas anteriormente. O modelo permite o trabalho orientado, tornando-o mais dinâmico e controlado. Os colaboradores, por sua vez, entendem de maneira holística o sistema, percebendo melhor o seu papel e a sua relevância. $\mathrm{O}$ ambiente de trabalho torna-se mais organizado, suscitando a harmonia e o sentimento de confiança e segurança entre as equipes.

Os procedimentos são realizados conforme modelo pré-estabelecido, visando a diminuir ou, se possível, eliminar desvios. Este modelo único propicia a escolha de materiais apropriados, a uma quantidade certa, para cada procedimento, evitando desperdício e possibilitando a análise de contas, assim como o planejamento de compras, refletindo diretamente no setor financeiro.

E, por fim, toda esta teia se revela eficaz, quando, aos olhos do cliente, se percebe a sua satisfação frente ao atendimento ofertado, ao ambiente que foi lhe apresentado, pela segurança que a equipe de saúde conseguiu transpassar, fazendo com que este período de aflição vivenciado fosse o menos traumático possível.

Por outro lado, padronizar processos exige trabalhar a cultura de toda uma equipe. As ferramentas gerenciais são caminhos utilizados para a orientação, a avaliação e a movimentação dos processos ou, ainda, de sistemas. Moldar ferramentas que atendam o propósito é uma tarefa atribulada.

Muitas vezes, programar novos desafios é visto pelas equipes como trabalho extra, ganhando o desdém das mesmas. Faz-se necessário, então, o poder de persuasão dos gerentes em motivar estes colaboradores. Relatam, os entrevistados, que é preciso envolvê-los desde o início na elaboração das ferramentas gerenciais, fazendo com que se desencadeie uma expectativa de bons resultados e, dessa forma, então, comprometê-los.

Outra questão levantada é a forma com que essas ferramentas são apresentadas. Estas devem despertar as atenções de cada um que as utiliza, ser atrativas, de fácil compreensão e, assim, seduzir a todos.

A problemática levantada neste artigo é relacionada ao tempo dedicado para o gerenciamento dos processos que, em muitas realidades, é prejudicado pelo excesso de atribuições que carrega o Enfermeiro. Fica, então, o propósito de abrir a estes profissionais espaço para que possam se dedicar à elaboração das ferramentas que aperfeiçoem os resultados. 
Por último, destaca-se a relevância que os indicadores têm dentro do sistema. Seus resultados são importantes fontes de consulta, que podem ser utilizados na avaliação da eficácia, assim como para promover possíveis ajustes dos processos trabalhados ou ainda orientar o planejamento do passo seguinte.

Entretanto, pelas entrevistas, fica evidente que os Enfermeiros, apesar do conhecimento teórico sobre esta ferramenta, não conseguem percebê-la claramente dentro do sistema ou ainda não têm tempo para analisar estes resultados.

\section{Referências}

1. Ribeiro MB, Coelho TP Jr, Baldam RL, Có FA, Zorzal MB. Processos em centro cirúrgico: desafios e proposta de solução. In: Anais do 29th Encontro Nacional de Engenharia de Produção; 2009 Oct 6-9; Salvador, Brasil. Salvador: ABEPRO; 2009 [acesso em 2010 Jul 15]. p. 1-12. Disponível em: http://www.cefetes.br/ pse/pos_producao/oficial/producao_da_equipe/enegep_2009/ marlowa_TN_STP_091_615_14596.pdf.

2. Sociedade Brasileira de Enfermeiros de Centro Cirúrgico. Práticas recomendadas SOBEEC. 5th ed. São Paulo: SOBECC; 2009.

3. Nepote MHA, Monteiro IU, Hardy E. Associação entre os índices operacionais e a taxa de ocupação de um Centro Cirúrgico Geral. Rev Latino-am Enfermagem. 2009;17(4):529-534. http://dx.doi. org/10.1590/S0104-11692009000400015

4. Fundação Nacional de Qualidade. Critérios compromissos com a excelência e rumo a excelência. São Paulo; 2009.
5. Abdala EC. A gestão orientada por processos: um estudo de caso em uma organização hospitalar brasileira. 2nd Congresso Brasileiro de Sistemas. Área Temática: Visão Sistêmica nas Áreas da Saúde; 2006, Ribeirão Preto, Brasil. São Paulo: FACEF; [acesso em 2010 Aug 16]. Disponível em: http://www.facef.br/quartocbs/ arquivos/41.pdf.

6. Rossi FR, Lima MADS. Fundamentos para processos gerenciais na prática do cuidado. Rev Esc Enferm USP. 2005;39(4):460-8. http://dx.doi.org/10.1590/S0080-62342005000400013

7. Lagioia UCT, Falk JA, Ribeiro Filho JF, Libonati JJ, Lopes JE. A gestão por processos gera melhoria de qualidade e redução de custos: o caso da unidade de ortopedia e traumatologia do Hospital de Clínicas da Universidade Federal de Pernambuco. R Cont Fin USP. 2008; 19(48):77-90.

8. Brasil. Ministério da Saúde. Conselho Nacional de Saúde. Resolução no 196, de 10 de outubro de 1996. Dispõe sobre as diretrizes e normas de pesquisa envolvendo seres humanos. Diário Oficial da República Federativa do Brasil; Brasília; out. 1996.

9. Bardin L. Análise de conteúdo. Lisboa: Ed. 70; 2002.

10. Cury A. Organizações e métodos. 7th ed. São Paulo: Atlas; 2000.

11. Nogueira LCL. Gerenciando pela qualidade total na saúde. 2nd ed. Belo Horizonte: EDG; 1999.

12. Marquis BL, Huston CJ. Administração e liderança em enfermagem: teoria e prática. 6th ed. Porto Alegre: Artmed; 2010.

13. Luongo J. Gestão de qualidade em saúde. São Paulo: Rideel; 2011.

14. Duarte IG, Ferreira DP. Uso de indicadores na gestão de um centro cirúrgico. Rev Adm Saúde. 2006;8(31):63-70.

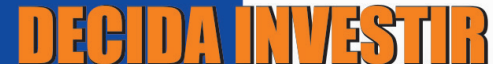

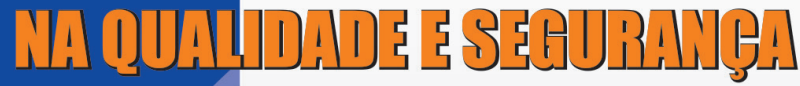

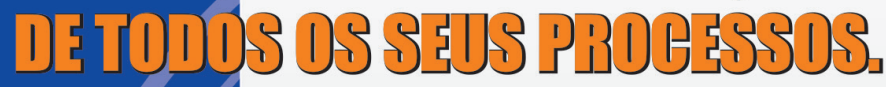

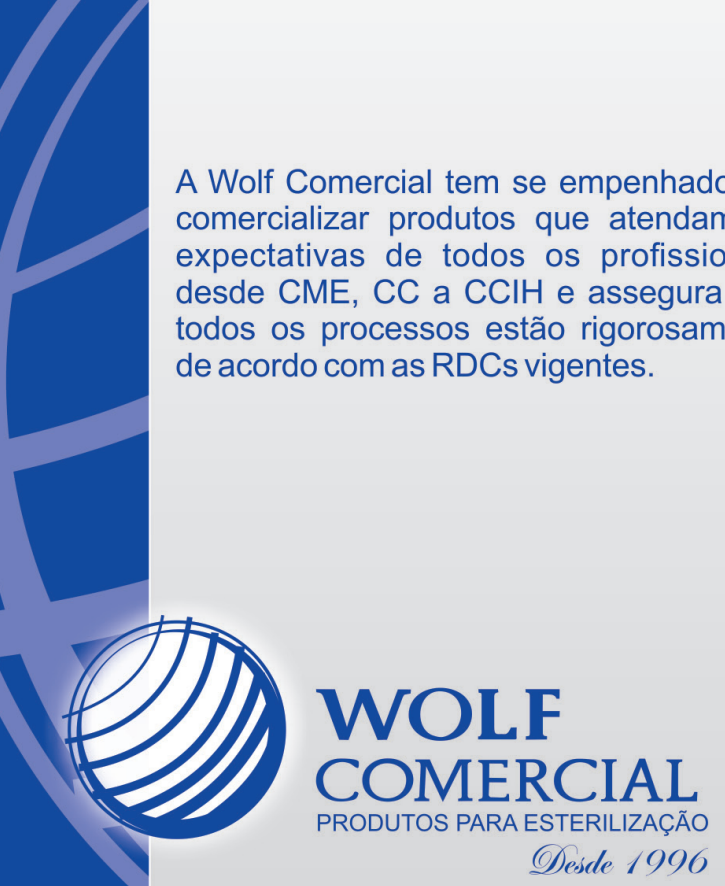

Acesse www.wolfcomercial.com.br e conheça toda linha

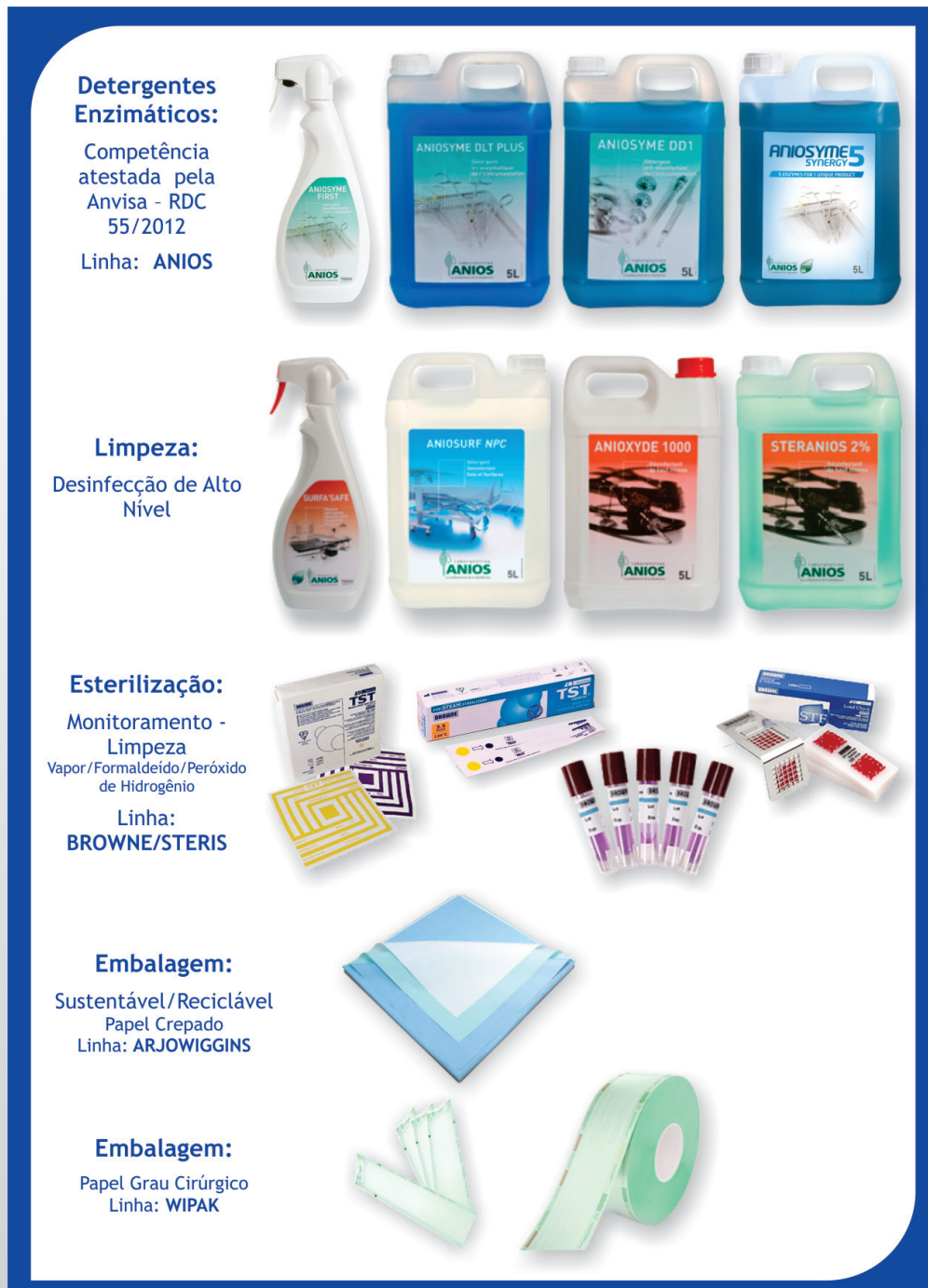

